\title{
CRITICAL SUCCESS FACTORS FOR ADOPTION OF CLOUD COMPUTING IN PUBLIC UNIVERSITIES IN KENYA
}

\author{
Charles Too', \\ Emily Bomett, \\ Catherine Kiprop \\ Department of Educational \\ Management and Policy Studies, \\ Moi University, \\ Kenya
}

\begin{abstract}
:
Cloud computing technology is a distributed computing approach whereby users access shared resources under various service models through the internet. It allows individual access to information technology resources through the internet upon demand. Cloud computing is an essentially growing terminology in the IT world and has become increasingly present in the life of institutions of higher learning. Institutions of higher learning consider cloud computing and construction of digital content platforms as a way of enhancing resource utilization and improvement of service delivery. The sudden and frenzied rush for cloud computing by universities has been aggravated by exponential growth in data traffic and the need for innovative learning such as e-learning and virtual classrooms amid COVID 19 pandemic (Kenya Education Network-KENET, 2021). Perhaps it is from that realization and the need to adhere to COVID 19 protocols that most public universities in Kenya have adopted cloud computing. In this study, we sought to find out the critical success factors for adoption of cloud computing in public universities in Kenya. The study set out three (3) objectives and consequently three (3) null hypotheses to guide it. Quantitative research design was adopted for this study. Similarly, International Business Machines-IBM (2011) model for cloud adoption offered theoretical guidance. At a confidence interval of $95 \%$, an online sample size calculator was used to arrive at three hundred and sixty two (362) respondents out of six thousand two hundred (6200) target population. Proportionate stratified random sampling technique and an online list randomizer were used to select respondents in the selected universities to participate in the study. Multiple regression was used to test the hypotheses in this study based on empirical data obtained by a survey questionnaire of thirty nine (39) questions from the two (2) public universities. Multiple regression results showed significant positive effect of Management Support $(\beta=.257)$, Technical Support
\end{abstract}

i Correspondence: email ngwolomet@gmail.com, ngwolomet@mu.ac.ke, emilybomett@gmail.com, emilybomett@mu.ac.ke, catekiprop@gmail.com, catekiprop@mu.ac.ke 
$(\beta=.353)$, and User Preparedness $(\beta=.475)$ on adoption of cloud computing at $p<.05$. Regression results gave a coefficient of determination $\mathrm{R}^{2}=.908$ which means $90.8 \%$ of the variation in adoption of cloud computing can be explained by Management Support, Technical Support, and User Preparedness combined. Based on the coefficient of determination $\left(\mathrm{R}^{2}\right)$, the three null hypotheses $\left(\mathrm{HO}_{1}, \mathrm{HO}_{2}\right.$, \& $\left.\mathrm{H}_{3}\right)$ were rejected at $\mathrm{p}<0.05$. Regression analysis showed that Management Support, Technical Support and User Preparedness are critical success factors in cloud adoption in public universities in Kenya. This study provides new and relevant insights to literature on cloud adoption in higher education service in Kenya.

Keywords: critical success factors, management support, technical support, user preparedness, adoption of cloud computing

\section{Introduction}

Cloud computing is one of the technologies that has been adopted by many organizations. With the competitive world, where technology is used to gain competitive advantage, many organizations have adapted themselves to the use of technology in order to remain competitive (Margianti \& Mutiara, 2019). Most organizations, especially institutions of higher learning in the world consider cloud technology as a critical intervention in their strife to improve their capacities in terms of delivery of service delivery.

Cloud computing revolution is fast sweeping its way through most institutions of higher learning globally (Borse \& Gokhale, 2019). This could be the reason why many institutions of higher learning in the world over have either embraced cloud technology or are on the road map to its adoption (Alzahrani, 2015). Although originally conceived for the banking sector, cloud technology has increasingly spread to other sectors of the economy, especially the education sector.

In many countries, the application of cloud technology flourishes as an efficient and scientific tool for reducing operational costs, improving service delivery, and streamlining academic activities in public universities (Borse \& Gokhale, 2019).

\section{Statement of the Problem}

In Kenya, the Vision 2030 blue print considers Information Communication and Technology (ICT) as part of Science Technology and Innovation (STI) which is one of the key pillars towards attainment of Millennium Development Goals (MDGs). Cloud computing (CC) is one of the innovative technologies that offers ingenious services to Information Communication and Technology (ICT) in institutions of higher learning in Kenya. Perhaps it is because of the importance and copious advantages of cloud computing that public universities in Kenya have increasingly adopted cloud computing (Waga, Makori \& Raba, 2014). Amidst reduction of offline classes, the technology 
provides students and staff seamless access to teaching and learning resources with greater flexibility through personalized virtual collaboration, communication and sharing of resources (Kurelovic, Rako \& Tomljanovic, 2013). Despite the recent and unprecedented adoption of cloud computing (CC) in institutions of higher learning, few studies have been carried out in this area (Mwavali, 2021) and therefore this study sought to analyse the critical factors which should be considered in order to successfully implement cloud technology in public universities Kenya.

\section{Theoretical and Model Underpinnings}

This study was based on International Business Machines-IBM (2011) model. The model comprised comprising of: (1) organizational environments; including top management support, re-engineering business process, effective project management, change management strategy, and institution-wide commitment; (2) people factors; including education and training, employee's attitude, project team and user involvement both at system requirements definition and cloud computing implementation; (3) technical problems; including suitability of software and hardware, IT maturity and data accuracy; (4) cloud computing vendor commitment; including vendor support, vendor tools and vendor and client partnerships; and (5) cultural impact; including organizational cultures and computer culture.

The model was chosen because it offers possibility of grouping complex issues into manageable constructs in adoption of new technologies.

\subsection{Conceptual Framework}

Owing to IBM (2011) model and literature on cloud computing a conceptual framework was generated. This study was conceptualized as presented in Figure 1.

Independent Variables

Critical Success Factors

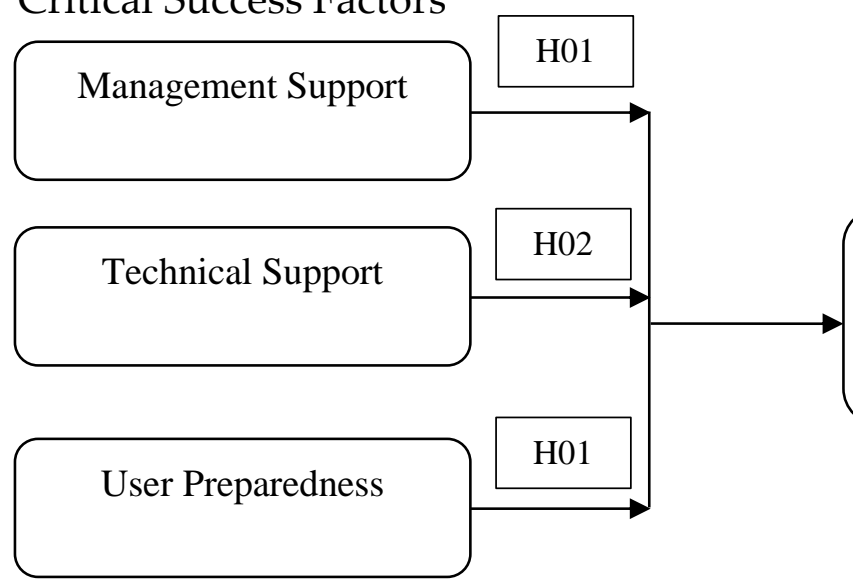

Dependent Variable

Adoption of Cloud

Computing 


\section{Literature Review}

Cloud computing is a technology where data and different applications are stored on storage networks and servers which are located in a remote place and accessed by the users via the Internet. This technology allows storage and access of data and programs in a seamless way over the internet instead of computer hard drives (Desai, Patel \& Patel, 2016). It is an on-demand, self-service global platforms of network technology which allows users to retrieve computing resources at any time at every place (Ghanem, 2019). On the other hand, institutions of higher learning need unchanged and consistent creativity and innovation so as to maintain cost effectiveness, efficiency and also for the provision of high quality services to staff and students. In this era of technology and elearning, students, staff and other stakeholders in institutions of higher learning, need to access various web-based information and resources with minimum down time. Moreover, cloud computing also solves issues to do with data management and assessment or analysis in teaching and research which are the core functions of public universities in Kenya (Waga, Makori \& Raba, 2014).

\subsection{Considerations in Adoption of Cloud Computing}

Many institutions of higher learning, especially universities have been in the rush to roll out cloud-based applications in the recent past. Initially, public universities had reservations about its adoption largely because of fear of the unknown and that the idea was still new (Onyango, 2016). However, the scenario has changed in the recent past with cloud computing being one of the fastest growing sectors of digital economy and is applicable to various activities of everyday life including education (Kurelovic, Rako \& Tomljanovic, 2013). The concerted efforts to utilize Cloud Computing (CC) in support of remote teaching and learning in public universities in Kenya during the COVID-19 pandemic have increasingly emerged (Kenya Education Network-KENET, 2021). The extraordinary disruption caused by the pandemic in Public Universities called for KENET to offer support and guidance on adoption of innovative ways so as to ensure continuity of learning in those institutions. Perhaps, the realization that cloud technology has copious advantages, secure and user friendly, has led to its full acceptance and vast implementation in institutions of higher learning. Consequently, KENET was mandated to transform research and learning using cloud-based educational platforms, resources and services that are deliberately designed to help universities navigate smoothly towards remote teaching and learning. The KENET data centres offer cloud computing using its own community infrastructure as an educational service that is used to host learning management systems, institution repository system, integrated library system and student information centres. The platforms allow universities to manage their services in a secure environment as well as install applications and operating systems of their choice (KENET, 2021). 


\subsection{Top Management Support}

Information adoption literature considers top management support as crucial and positively related to successful implementation of cloud computing in most organisations (Gangwer, 2015). The support is in terms of corporate values, culture, allocation of resources, conducive infrastructural platforms, and support during the change process (Ramdani \& Kawelek, 2007; Borgman et al. 2013; Makena, 2013; Gangwer, 2015; Yigitbasioglu, 2015). For cloud computing to be a success in most organisations in Kenya, those in leadership positions must be ready to champion and support it (Ogwel et al., 2020)

\subsection{Technical Support}

Technical support is one of the factors which facilitate successful implementation and adoption of cloud computing in most institutions (Cegielski et al., 2012; Tweel, 2012; Makena, 2013; Ogwel et al., 2020). Technical support in cloud computing resonates around the cloud service providers and is the main driving factor in ensuring that cloud information is available at all times or whenever needed (Gangwar, 2015). The web services that support institutions of higher learning in Kenya include CRM and ERP which are available in software as a service (KENET, 2021).

\subsection{User Preparedness}

Cloud computing as a complex system requires that the end users are adequately prepared through appropriate training and education before it is rolled out (Gangwar, 2015). User preparedness help in reducing ambiguity, anxiety and stress among users while improving the users' perception on ease of use and usefulness (Munguti \& Opiyo, 2018). Consequently, there have been various ICT trainings given to end users so as to help them navigate and interact with e-resources through online platforms with ease (Omwansa, Waema \& Omwenga, 2014).

The literature above demonstrates that top management support, technical support and user preparedness are key parameters which should be considered in adoption of cloud technology. However, it would be interesting to find out whether the same factors are significant in cloud adoption in institutions of higher learning in developing countries. It was against this background that this study sought to assess the critical success factors in cloud adoption in public universities in Kenya.

The study set out the following hypotheses:

H01: Management Support has no Statistically Significant Effect on Cloud Computing Adoption in Public Universities in Kenya.

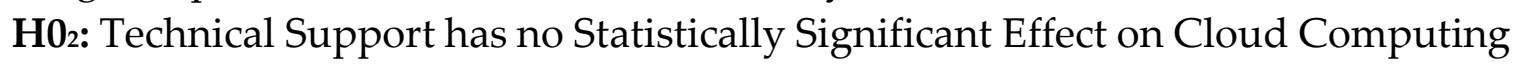
Adoption in Public Universities in Kenya.

H0$_{3}$ : User Preparedness has no Statistically Significant Effect on Cloud Computing Adoption in Public Universities in Kenya. 


\section{Methods}

\subsection{Sample}

This study was carried out in two (2) public universities in Kenya. The universities had approximately six thousand two hundred $(6,200)$ members of staff. An online sample size calculator was used to determine the sample size that would precisely reflect the target population. At a confidence level of $95 \%$, a sample of three hundred and sixty two (362) was arrived at. Stratified simple random sampling technique, and more specifically an online list randomizer was used to proportionately select respondents in the two public universities from the following Strata; Senate Members (15), Teaching non Senate Staff (46), Senior Administrative, Library and Technical Staff (96), Middle (101), Junior Staff (104).

This study used the following two instruments; questionnaires and document analysis. The main instrument was the questionnaire which was administered on three hundred and sixty two (362) members of staff in order to obtain information on management support, technical support, user preparedness, and cloud adoption. Two hundred and forty two (242) questionnaires were duly filled and returned. The questionnaires comprising of thirty nine (39) questions were closed ended and in the Likert type of scale ranging from: 'Strongly Disagree' (SD), Disagree (D), Neutral (N), Agree (A), Strongly Agree (SA). Document analysis was used to find out the number of staff in the universities.

\subsection{Independent Variables}

\subsubsection{Management Support}

This study operationalized management support in terms of consideration of cloud computing in budget allocation, having cloud computing as part of its vision, championing cloud computing initiatives, adequate staffing of IT department, availability of cloud computing infrastructure, articulation advantages of cloud computing, reengineering of procedures to accommodate cloud computing, provision of sufficient information on cloud computing, commitment towards cloud computing initiatives, and development of proper road map towards cloud computing. Cronbach's Alpha test revealed that the responses were internally consistent with a coefficient of 790 which satisfied Sekeran (2000) benchmark of $\alpha=0.7$. Shapiro-Wilk test showed that the responses were normally distributed at $p>.05$ with a coefficient of .078. Multiple regression showed that the responses had tolerable multicollinearity with a Variance Inflation Factor loading of 2.439 which satisfied O'brien (2007) benchmark of multicollinearity. The Kaiser-Meyer-Olkin (KMO) test gave a value of .740, while the Bartlett's test was significant at (Approx $\chi^{2}=2738.819, p=.000$ ) which confirmed the appropriateness of the factor analysis for management support. 


\subsubsection{Technical Support}

Technical support was operationalized in terms of requisite IT infrastructure in place, competent staff to handle cloud computing, sensitization of potential users on cloud computing, adequate information system support for cloud computing, well developed computing platforms, efficient IT system, university enterprise system suited for cloud computing, users having good computer knowledge, modern IT environment, thorough testing of cloud before 'go-live' stage, and vendors offering technical support and follow up. Cronbach's Alpha test revealed that the responses were internally consistent with a coefficient of .781 which satisfied Sekeran (2000) benchmark of $\alpha=0.7$. Shapiro-Wilk test showed that the responses were normally distributed at p>.05 with a coefficient of .087 . Multiple regression showed that the responses had tolerable multicollinearity with a Variance Inflation Factor loading of 3.125 which satisfied O'brien (2007) benchmark of multicollinearity. The Kaiser-Meyer-Olkin (KMO) test gave a value of .637, while the Bartlett's test was significant at (Approx $\chi^{2}=1918.838, p=.000$ ) which confirmed the appropriateness of the factor analysis for technological support.

\subsubsection{User Preparedness}

User preparedness was operationalized in terms of user being conversant with the cloud system, trained on cloud computing, adequate cloud competencies, positive attitude towards cloud computing, readiness to upgrade to new technologies, upbeat about cloud computing, and familiarity with cloud computing. Cronbach's Alpha test revealed that the responses were internally consistent with a coefficient of .708 which satisfied Sekeran (2000) benchmark of $\alpha=0.7$. Shapiro-Wilk test showed that the responses were normally distributed at $p>.05$ with a coefficient of .789. Multiple regression showed that the responses had tolerable multicollinearity with Variance Inflation Factor loading 1.988 which satisfied O'brien (2007) benchmark of multicollinearity. The Kaiser-Meyer-Olkin (KMO) test gave a value of .572, while the Bartlett's test was significant at (Approx $\chi^{2}=850.613, p=.000$ ) which confirmed the appropriateness of the factor analysis for user preparedness.

\subsection{Dependent Variable-Cloud Adoption}

In this study, cloud adoption was measured in terms of strength of cloud computing, increase in efficiency and accountability via cloud computing, periodic evaluation and monitoring of cloud computing, cloud computing aligned to a department, assisted in definition of roles, detailed installation plans, adequate system testing, requisite skills by system users, and proper planning and coordination of cloud computing. Cronbach's Alpha test revealed that the responses were internally consistent with a coefficient of .780 which satisfied Sekeran (2000) benchmark of $\alpha=0.7$. Shapiro-Wilk test showed that the responses were normally distributed at $\mathrm{p}>.05$ with a coefficient of .778 . The Kaiser-MeyerOlkin (KMO) test gave a value of .649 , while the Bartlett's test was significant at (Approx $\chi^{2}=1332.009, p=.000$ ) which confirmed the appropriateness of the factor analysis for cloud adoption. 


\subsection{Model and Analysis}

In order to establish the critical success factors in cloud adoption in public universities in Kenya, the aggregate mean scores of the independent variables; management support (MS), technical support (TS), and user preparedness (UP) were regressed on the aggregate mean scores of the dependent variable adoption of cloud computing (ACC): $\mathrm{ACC}=\beta_{0}+\beta_{1} \mathrm{MS}+\beta_{2} \mathrm{TS}+\beta_{3} \mathrm{UP}+\varepsilon$.

\section{Limitations of the Study}

The major limitation was on external validity or generalizability of the findings of the study to other public universities. Given the sample size of 362 respondents and 242 valid questionnaires, the study was faced with a limitation as to whether the findings of the study were generalizable to other universities on the basis of this study alone. Whereas the study attempted to capture all variables used to measure adoption of cloud computing (ACC), management support (MS), technical support (TS), and user preparedness (UP) in public universities, the researcher reckons that to achieve a complete and accurate reflection of those constructs, is hardly fully achievable.

\section{Results}

\subsection{Correlation Analysis}

Correlation analysis was done to determine relationships between the study variables. Pearson product moment correlation coefficient test showed that the there was strong positive relationship between the study variables and therefore it was safe to run regression analysis as shown in Table 1.

Table 1: Correlation Matrix (N=242)

\begin{tabular}{|l|c|c|c|c|}
\hline & $\mathbf{1}$ & $\mathbf{2}$ & $\mathbf{3}$ & $\mathbf{4}$ \\
\hline 1. Adaption of Cloud Computing & $\mathbf{1}$ & & & \\
\hline 2. Management Support & $.703^{* *}$ & 1 & & \\
\hline 3. Technical Support & $.809^{* *}$ & $.731^{* *}$ & 1 & \\
\hline 3. User Preparedness & $.840^{* *}$ & $.603^{* *}$ & $.664^{* * *}$ & 1 \\
\hline
\end{tabular}

**. Correlation is significant at the 0.01 level (2-tailed)

Source: Survey Data (2021), N=242

\subsection{Relationship between ACC and MS, TS, UP}

The aggregate mean scores from data on adoption of cloud computing (independent variable) were regressed on the aggregate mean scores from data on management support, technical support, and user preparedness (dependent variables). Hypotheses set were tested using multiple regression method and the model set constructed. 
Table 2: Significance of Regression Analysis of MS, TS, UP on ACC (N=242)

\begin{tabular}{|l|l|c|c|c|c|c|}
\hline ANOVA $^{\mathbf{b}}$ & Sum of Squares & df & Mean Squares & F & Sig. \\
\hline Model & & 302.074 & 3 & 102.066 & 816.528 & $.000^{\mathbf{a}}$ \\
\hline 1 & Regression & 26.152 & 238 & .125 & & \\
\hline & Residual & 328.226 & 241 & & & \\
\hline & Total & $\begin{array}{l} \\
\text { a. Predictors: (constant), MS, TS, UP } \\
\text { b. Dependent Variable, ACC }\end{array}$ \\
\hline
\end{tabular}

Source: Survey Data (2021)

ANOVA results based on the F-test $(F=816.528, p=000)$ showed that the multiple regression model was robust enough to explain the adoption of cloud computing using management support, technical support, and user preparedness as the critical success factors in Table 2.

The model also showed that $\mathrm{R}^{2}$ (coefficient of determination) is 0.908 , which means that approximately $90.8 \%$ of the variation in adoption of cloud computing can be explained by management support, technical support, and user preparedness combined as shown on Table 3.

Table 3: Model Summary for Regression of MS, TS, UP on ACC (N=222)

\begin{tabular}{|c|c|c|c|c|}
\hline Model & $\mathbf{R}$ & $\mathbf{R}$ Square & Adjusted R Square & Standard Error \\
\hline 1 & $.953^{\mathrm{a}}$ & .908 & .887 & .34305 \\
\hline
\end{tabular}

Source: Survey Data (2021)

Because management support, technical support, and user preparedness combined significantly predicted variations in adoption of cloud computing, $F(3,238)=816.528$, $p$ $<0.05, R^{2}=0.908$, and the respective beta coefficients $(\beta=.257, \beta=.353, \beta=.475, p<0.05)$, the Hypothesis $1\left(\mathrm{H}_{01}\right)$, Hypothesis $2\left(\mathrm{H}_{02}\right)$ and Hypothesis $3\left(\mathrm{H}_{03}\right)$ were therefore safely rejected.

On the basis of the results on Table 4, the following model was constructed to explain the effect of individual factors on cloud computing in public universities in Kenya:

$\mathrm{ACC}=-.047+.257 \mathrm{MS}+.353 \mathrm{TS}+.475 \mathrm{UP}$.

Where; ACC = adoption of cloud computing, MS = management support, $\mathrm{TS}=$ technical support, UP = user preparedness and $-.047=\mathrm{y}$-intercept-constant. 
Table 4: Beta Coefficients of Multiple Regression of MS, TS, UP on ACC (N=242)

\begin{tabular}{|c|c|c|c|c|c|c|c|c|}
\hline \multirow[b]{3}{*}{ Model } & & \multicolumn{4}{|c|}{ Coefficients ${ }^{\mathrm{a}}$} & \\
\hline & & \multicolumn{2}{|c|}{ Unstandardized } & \multicolumn{2}{|c|}{ Standardized } & \multirow[t]{2}{*}{ Sig. } & \multirow[t]{3}{*}{ Tol. } & \multirow[t]{3}{*}{ VIF } \\
\hline & & B & SE & Beta & $t$ & & & \\
\hline \multirow[t]{4}{*}{1} & (Constant) & -.047 & .059 & & 3.490 & .000 & & \\
\hline & MS & .257 & .027 & .202 & 6.576 & .000 & .410 & 2.439 \\
\hline & TS & .353 & .023 & .323 & 9.880 & .000 & .320 & 3.125 \\
\hline & UP & .475 & .025 & .547 & 20.042 & .000 & .503 & 1.988 \\
\hline
\end{tabular}

Source: Survey Data (2021)

\section{Discussion}

\subsection{Effect of Management Support on Adoption of Cloud Computing}

The result of the study indicated that management support had a positive and significant effect on cloud computing $(\beta=.257, \mathrm{p}<.05)$. The results suggest that as the level of management support increases, so the level of cloud computing adoption. Top management support has a crucial role in initiating, implementing and adopting cloud computing. It is the organizational leadership that typically supports initiatives, provides resources, participate in decision making and set organizational strategies and direction for cloud adoption (Ogwel et al., 2020). Cloud computing adoption must therefore receive approval from management besides them demonstrating strong commitment for the successful implementation of cloud computing in any organization.

According to Gangwar (2015), successful adoption of cloud computing require strong leadership, commitment, and participation from top management. The roles of management in adoption of cloud computing include establishing reasonable goals for adoption of cloud computing, exhibiting strong commitment for its implementation and communication the corporate cloud computing strategy to all the employees.

The results link well with literature and empirical findings by (Ramdani \& Kawalek, 2007; Borgman et al., 2013; Makena 2013; Yigitbasioglu, 2015; Ogwel et al., 2020) on the effect of top management support on adoption of cloud computing in organisations. Drawing from these findings, top management give the cloud computing the necessary impetus for its successful adoption in any organization.

\subsection{Effect of Technical Support on Adoption of Cloud Computing}

Hypothesis $2\left(\mathrm{H}_{02}\right)$ predicted that technical support does not significantly affect cloud computing adoption. The results indicated that technical support has a significant positive effect on cloud computing adoption $(\beta=.353, p=<0.05)$. The results suggest that as the level of technical support increases, so does the level of cloud computing adoption. This in effect means having suitable software and right hardware is a fundamental step in adoption of cloud computing in an organization. The findings support literature by (Cegielski et al., 2012; Tweel, 2012; Hudson, 2013; Makena, 2013; Ogwel et al., 2020) on the significant role of technical support in adoption of cloud computing in organisations. 


\subsection{Effect of User Preparedness on Adoption of Cloud Computing}

Hypothesis $3\left(\mathrm{H}_{03}\right)$ stated that user preparedness does not have significant effect cloud computing adoption. The results found that there exists a positive significant effect of user preparedness on cloud computing adoption $(\beta=.475, \mathrm{p}<0.05)$. The finding suggests that higher user preparedness leads to higher cloud computing adoption in organisations. These results support the literature and findings by Munguti \& Opiyo (2018) on the need to appropriately prepare users' perceptions and competencies for successful adoption of cloud computing in organisations.

\section{Conclusion}

This study successfully extended knowledge by studying and testing whether management support, technical support, and user preparedness affected adoption of cloud computing. Many innovative organisations have found that cloud computing adoption provides them with the flexibility to take control of their innovation processes while streamlining other business processes and controlling cost. This study has demonstrated that management support, technical support, and user preparedness go a long way in ensuring that the adoption of cloud computing is a success. Providers of cloud system services require suitable platforms for developing and installing their applications. They are facing the challenge of integrating technology-oriented system with business processes and this can be overcome by considering management support, technical support, and user preparedness as the remedy for the challenges. Based on the findings of this study and analysis of relevant studies, critical success factors for adopting cloud computing in public universities in Kenya have been put forward.

In conclusion, the findings of this study have important implications for academic, management practice and human resources. As scholarly inquiries into the notion of critical success factors for the adoption of cloud computing has remained conceptual to date, this research is one of the attempts to test the concepts in an empirical setting. Institutions of higher learning may endorse the validity of incorporating management support, technical support, and user preparedness in order to enhance the successful implementation of cloud computing.

\section{Recommendations}

Several practical implications arise from the findings of this study. The findings have demonstrated the importance management support, technical support, and user preparedness in the adoption of cloud computing. Organizations that want to capitalize on the innovative technologies like cloud computing must ensure that managers explicitly give the project the requisite support. Also, the organization must give the necessary technological support for ease of adoption to cloud computing. Furthermore, the users of the cloud computing technology must be prepared for ease of uptake of this innovation. Therefore, efforts to increase cloud computing adoption can be 
complemented by efforts to enhance the identified critical success factors of management support, technical support, and user preparedness by the organization.

\title{
Conflict of Interest Statement
}

The authors declare no conflicts of interests.

\begin{abstract}
About the Authors
Charles Too is a Lecturer in the Department of Educational Management and Policy Studies, Moi University, Kenya. The author has published articles in peer reviewed journals and has research interests on: Leadership in Education, Quality Management Systems in Education, Performance Contracts and Policy Issues in Education. He is a trained Quality Internal Auditor (ISO 9001:2015 standards). Charles has tremendous passion for Information Technology and is a resource person in applied statistics and data analysis in research.
\end{abstract}

Emily J. Bomett has been working as a senior lecturer with a $\mathrm{PhD}$ in the School of Education, Department of Education Management and Policy Studies, Moi University, Eldoret, Kenya. She has written papers in journals which covers the following areas: gender participation, retention with particular interest in the boy child and the girl mother; leadership and management particularly in strategic management and planning: Information Technology. Her Professional expertise is in management, leadership and administration for educationists and institutional managers.

Catherine Kiprop is an Associate Professor in the Department of Educational Management and Policy Studies, Moi University, Kenya. She has published widely in peer reviewed journals and currently serves as editor of two book projects. Her research interests include but are not limited to: school management and leadership, strategic management and gender issues.

\section{References}

Alzahrani I, 2015. The Use of Cloud Computing in Higher Education: Reality, Expectation and Challenges. https:/www.westeastinstitute.com/wpcontent/uploads/2015/07/Ibraheem-Alzahrani.pdf

Borgman H. P, Bahli B, Heier H, Schewski F, 2013. Cloud Rise: Exploring Cloud Computing Adoption and Governance with the TOE Framework. DOI 10.1109/HICSS.2013.132

Borse Y, Gokhale S, 2019. Cloud Computing Platform for Education System: A Review. International Journal of Computer Applications 177: 41-45 http://dx.doi.org/10.5120/ijca2019919475

Cegielski C. G, Farmer L. A, Wu Y, Hazen B. T, 2012. Adoption of Cloud Computing Technologies in Supply Chains. The International Journal of Logistics Management 23: 184-211 http://dx.doi.org/10.1108/09574091211265350 
Desai T, Patel R, Patel P, 2016. Cloud Computing in Education Sector. International Journal for Innovative Research in Science and Technology 2: 191-194 http://www.ijirst.org/articles/I]IRSTV2I10084.pdf

Gangwar H, Date H, Ramaswamy R, 2015. Understanding Determinants of Cloud Computing using an Integrated TAM-TOE Model. Journal of Enterprise Information Management 28: 1-31 DOI: 10.1108/JEIM-08-2013-0065

Government of Kenya, 2019. National Information Communications and Technology (ICT) Policy. https://www.ict.go.ke/wp-content/uploads/2019/12/NATIONALICT-POLICY-2019.pdf. Accessed on 5 August 2021

Ghanem B. M, 2019. Application of Cloud Computing in the Field of Education: Google Apps as an Example. International Journal of Advanced Research and Publications 3: 25-34 http://www.ijarp.org/published-research-papers/june2019/ApplicationOf-Cloud-Computing-In-The-Field-Of-Education-Google-Apps-As-An-

Example.pdf

Kurelovic E. K, Rako S, Tomljavonic J, 2013. Cloud Computing in Education and Student's

Needs.

https://www.researchgate.net/publication/261424656 Cloud computing in educ ation and student $\% 27 \mathrm{~s}$ needs

Makena J. N, 2013. Factors that Affect Cloud Computing Adoption by Small and Medium Enterprises in Kenya. International Journal of Computer Applications Technology and $\quad$ Research 517-521. https://ijcat.com/archives/volume2/issue5/ijcatr02051003.pdf

Margianti E. S, Mutiara A. B, 2015. Application of Cloud Computing in Education. DOI: 10.13140/RG.2.1.3506.0247

Munguti S. N, Opiyo E, 2018. Factors Influencing the Adoption of Cloud Computing in Software Development Companies in Kenya. International Academic Journal of $\begin{array}{lllll}\text { Information } \quad \text { Systems } \quad \text { and } & \text { Technology }\end{array}$ https://www.iajournals.org/articles/iajist v2 i1 126 144.pdf

Mwavali A, 2021. A Framework for Cloud Computing Adoption by SMEs in Kenya. World Journal of Innovative Research 10: 111-117 https://doi.org/10.31871/WJIR.10.4.29

O'Brien R. M, 2007. A Caution Regarding Rules of Thumb for Variance Inflation Factors. http://dx.doi.org/10.1007/s11135-006-9018-6

Ogwel B, Otieno G, Otieno G. O, 2020. Cloud Computing by Public Hospitals in Kenya: A Technological, Organisational and Behavioural Perspective. International Journal of Scientific and Research Publications 10: 33-43 http://dx.doi.org/10.29322/IJSRP.10.01.2020.p9707

Omwansa T. K, Waema T. M, Omwenga B, 2014. Cloud Computing in Kenya: A 2013 Baseline Survey. https://www.researchgate.net/publication/263059145 Cloud Computing in Ken ya A baseline survey 
Onyango D. O, 2014. Using Cloud Computing in Higher Education: A Strategy to Address Trust Issues in Adoption of Cloud Services in Kenyan Public and Private Universities. MSc Thesis, University of Nairobi, Kenya.

Ramdani B, Kawelek P, 2007. SME Adoption of Enterprise Systems in North West of England. An Environmental Technological and Organisational Perspective. International Federation for Information Processing 235: 409-430. http://dl.ifip.org/db/conf/ifip8-6/ifip8-6-2007/RamdaniK07.pdf

Sekeran G, 2003. Case validity in research undertaking. Oxford University Press, Oxford Tweel A, 2012. Examining the Relationship between Technological, Organisational and Environmental Factors and Cloud Adoption. Ph.D. Thesis, Northcentral University, San Diego.

Waga D, Makori, E, Rabah K, 2014. Utilisation of Cloud Computing in Education and Research to the Attainment of Millennium Development Goals and Vision 2030 in Kenya. Universal Journal of Educational Research 2: 193-199 DOI: 10.13189/ujer.2014.020212

Yigitbasioglu O, 2015. The Role of Institutional Pressures and Top Management Support in the Intention to Adopt Cloud Computing Solutions. Journal of Enterprise Information Management 28: 579-594 https://doi.org/10.1108/JEIM-09-2014-0087 
Creative Commons licensing terms

Author(s) will retain the copyright of their published articles agreeing that a Creative Commons Attribution 4.0 International License (CC BY 4.0) terms will be applied to their work. Under the terms of this license, no permission is required from the author(s) or publisher for members of the community to copy, distribute, transmit or adapt the article content, providing a proper, prominent and unambiguous attribution to the authors in a manner that makes clear that the materials are being reused under permission of a Creative Commons License. Views, opinions and conclusions expressed in this research article are views, opinions and conclusions of the author(s). Open Access Publishing Group and European Journal of Education Studies shall not be responsible or answerable for any loss, damage or liability caused in relation to/arising out of conflicts of interest, copyright violations and inappropriate or inaccurate use of any kind content related or integrated into the research work. All the published works are meeting the Open Access Publishing requirements and can be freely accessed, shared, modified, distributed and used in educational, commercial and non-commercial purposes under a Creative Commons Attribution 4.0 International License (CC BY 4.0). 